\title{
Composite analysis of a major sudden stratospheric warming
}

\author{
K. Hocke ${ }^{1,2}$, M. Lainer ${ }^{1,2}$, and A. Schanz ${ }^{1,2}$ \\ ${ }^{1}$ Institute of Applied Physics, University of Bern, Bern, Switzerland \\ ${ }^{2}$ Oeschger Centre for Climate Change Research, University of Bern, Bern, Switzerland
}

Correspondence to: K. Hocke (klemens.hocke@iap.unibe.ch)

Received: 20 March 2015 - Revised: 29 May 2015 - Accepted: 01 June 2015 - Published: 25 June 2015

\begin{abstract}
We present the characteristics of a major sudden stratospheric warming (SSW) by using the composite analysis method and ERA Interim reanalysis data from 1979 to 2014. The anomalies of the parameters total ozone column density (TOC), temperature $(T)$, potential vorticity (PV), eastward wind $(u)$, northward wind $(v)$, vertical wind $(w)$, and geopotential height $(z)$ are derived with respect to the ERA Interim climatology (mean seasonal behaviour 1979 to 2014). The composites are calculated by using the time series of the anomalies and the central dates of 20 major SSWs. Increases of up to 90 Dobson units are found for polar TOC after the SSW. Polar TOC remains enhanced until the summer after the major SSW. Precursors of the SSW are a negative TOC anomaly 3 months before the SSW and enhanced temperature at $10 \mathrm{hPa}$ at mid-latitudes about 1 month before the SSW. Eastward wind at $1 \mathrm{hPa}$ is decreased at mid-latitudes about 1 month before the SSW. The $1 \mathrm{hPa}$ geopotential height level is increased by about $500 \mathrm{~m}$ during the month before the SSW. These features are significant at the $2 \sigma$ level for the mean behaviour of the ensemble of the major SSWs. However, knowledge of these precursors may not lead to a reliable prediction of an individual SSW since the variability of the individual SSWs and the polar winter stratosphere is large.
\end{abstract}

Keywords. Meteorology and atmospheric dynamics (middle atmosphere dynamics)

\section{Introduction}

The present study shows the typical behaviour of a major sudden stratospheric warming (SSW) and its effects on the atmospheric composition, thermal state, and dynamics. The SSW phenomenon has already been investigated and reviewed in the past, e.g. by Matsuno (1971), Scherhag (1952), and Schoeberl (1978). In short, planetary wave-breaking in the middle atmosphere leads to a reversal of the polar stratospheric vortex in the winter hemisphere. SSWs are generally important for the meridional circulation of the middle atmosphere. Marshall and Scaife (2010) used a high resolution numerical weather prediction model with a maximum of $84 \mathrm{~km}$ altitude. They found that major SSWs can be predicted with a lead time of 12 days. Flury et al. (2009) studied the response of the atmospheric composition to a SSW and found ozone depletion and polar stratospheric clouds over Europe. Liu et al. (2011) performed an ozone budget analysis and found that ozone inside the polar vortex is enhanced by 2628 DU due to the SSW. Baldwin and Dunkerton (2001) reported that SSWs cause anomalous weather regimes 60 days after the SSW in the troposphere.

In the present study, we follow the conservative definition of a SSW given by McInturff (1978). A major SSW is associated with a sudden warming $(>20 \mathrm{~K}$ ) of the stratosphere poleward of $60^{\circ} \mathrm{N}$ and at $10 \mathrm{hPa}$. Further, the zonal wind reverses from eastward to westward flow for at least 5 days. The date of the zonal wind reversal $(u=0)$ is taken as the central date of the SSW. The central date is ideally suited to be the timing mark of the composite analysis. Different to previous studies, the composite analysis is taken here for a longer time interval before and after the SSW ( \pm 90 days for the dynamic parameters and \pm 180 days for total ozone with respect to the central date of the SSW). The long time interval is reasonable since the life time of ozone in the lower stratosphere is several months. A case study by Tomikawa et al. (2012) showed that the stratopause is elevated after a major SSW over a time interval of 90 days. In addition, one can argue that the vortex onset is usually in November for the Northern Hemisphere, while the SSW most often occurs in late January. The onset of the polar vortex might already be related to the preconditioning of the stratospheric flow. 
Smith (1992) simulated the effect of preconditioning on the occurrence of major and minor SSWs. She found that an upward propagating, planetary wave pulse can initialize a SSW when the lower stratospheric flow is preconditioned. The area size of the polar vortex and the planetary wave refractive index can indicate the preconditioning. The simulations of Smith (1992) were limited to the discussion of dynamical parameters and to a time interval from 20 days before to 20 days after the SSW central date. Evaluating meteorological reanalysis data with a composite analysis from 10 days before to 10 days after the SSW central date, Martius et al. (2009) found that a tropospheric blocking can initialize a SSW. However, Taguchi (2008) found no significant link between tropospheric blockings and SSWs.

Limpasuvan et al. (2004) investigated the life cycle of SSWs by using a composite analysis of meteorological reanalysis data with epoch times from 40 days before to 40 days after the SSW central date. The EP flux divergence reaches an extrema in the stratosphere during the so-called SSW growth phase (from 22 to 8 days before SSW central date). Charlton and Polvani (2007) performed a composite analysis (from 60 days before to 60 days after the SSW central date) based on different meteorological reanalysis data sets. In difference to the present study, they averaged out the high-latitude region, with the advantage of studying the altitude dependence of SSWs. They found that the heat flux at $100 \mathrm{hPa}$ is increased during the 20 days before the SSW. Miller et al. (2013) performed composite analysis for the time interval from 15 days before to 15 days after the SSW central date. They looked particularly for mesospheric precursors in the zonal wind, and they found longitudinal dependence of the mesospheric flow before the central date of the SSW.

Matthewman et al. (2009) performed a study on the 3-D shape of the dynamical polar vortex from 10 days before to 10 days after the SSW central date. As in other studies, they distinguished between vortex-splitting SSWs and vortex-displacement SSW so that they can discuss the longitudinal and latitudinal variations of the SSW events in polar stereographic composite plots. In the present study, no separation of major SSWs into vortex-splitting and vortexdisplacement events is performed since we focus on the discussion of zonal means, and the effects of vortex-splitting and vortex-displacement partly vanish in the zonal mean. Further, the separation of the 20 major SSWs into two ensembles has the penalty that the number of SSW events in each ensemble is reduced (only about 10 instead of 20). Thus the standard deviation of the mean would become larger and it might be more difficult to derive statistically significant results. Further, the number of viewgraphs would be doubled which is also not desired for the present study.

In the following we describe the evolution of a major SSW by means of composite analysis. As mentioned above, the time interval of the epoch time is longer for the present study compared to previous studies. We also discuss the be- haviour of the parameter total ozone which was not covered by previous composite analysis studies. The aim is to find SSW-related features in the composites which might have been overseen by others. The detection of such SSW-related features may enhance our understanding of the SSW phenomenon and may lead to a better prediction of SSWs by the recognition of SSW precursors.

\section{Data set and data analysis}

\subsection{Meteorological reanalysis data: ERA Interim}

ERA Interim reanalysis provides vertical profiles of ozone volume mixing ratio with a time resolution of $6 \mathrm{~h}$ from 1979 to present. While the absolute values of the ozone profiles may have uncertainties of about 10 to $20 \%$, the spatial and temporal variations of the estimated ozone distribution on larger scales (say horizontal scales $>1000 \mathrm{~km}$ and temporal scales $>5$ days) are reliable since the ozone distribution of ERA Interim is driven by observations from ozonesondes and satellites and by the dynamics of the ECMWF global circulation model (Dee et al., 2011). The upper boundary of the assimilation model at about $65 \mathrm{~km}(0.1 \mathrm{hPa})$ may lead to uncertainties in the upper stratospheric circulation and ozone transport. However, ERA Interim can be regarded as stateof-the-art meteorological reanalysis; the present study can take advantage of the numerous past improvements in atmospheric modelling and observation techniques.

\subsection{Climatology}

In the present study, we discuss anomalies of the zonal mean data of ERA Interim. The mean seasonal behaviour is derived from the 36 years of ERA Interim data (1979 to 2015). The data are sorted and averaged for the day of year. Then the mean seasonal series is obtained by means of a 60-day low pass filter (digital non-recursive filter with a fast response time). An example of the mean seasonal behaviour of TOC (total ozone column) at $80^{\circ} \mathrm{N}$ is shown by the red line in Fig. 1.

\subsection{Composite analysis and significance}

We consider all major SSWs that have taken place in the Northern Hemisphere from 1980 to 2014. The SSW of 1979 is not taken since it lays at the edge of the available ERA Interim data set. The timing marks of the 20 major SSWs are given in Table 1. A timing mark corresponds to the central date of a major SSW. This central date is the time when the zonal wind at $10 \mathrm{hPa}$ and poleward of $60^{\circ} \mathrm{N}$ reverses from eastward wind to westward wind. In the present study we derive the central dates directly from the time series of zonal wind and temperature from the ERA Interim data set. For each latitude belt, we compute the anomalies of the different parameters at various pressure levels. Anomaly data segments from 180 days before the central date to 180 days after 
Table 1. Central dates of the 20 major SSWs

$\begin{array}{rr}\text { 28 February 1980 } & \text { 25 February 1999 } \\ \text { 03 April 1982 } & \text { 01 February 2001 } \\ \text { 20 February 1984 } & \text { 28 December 2001 } \\ \text { 29 December 1984 } & \text { 15 February 2002 } \\ \text { 21 January 1987 } & \text { 16 January 2003 } \\ \text { 06 December 1987 } & \text { 02 January 2004 } \\ \text { 12 March 1988 } & \text { 21 January 2006 } \\ \text { 19 February 1989 } & \text { 23 January 2009 } \\ \text { 19 March 1992 } & \text { 23 January 2010 } \\ \text { 14 December 1998 } & \text { 06 January 2013 }\end{array}$

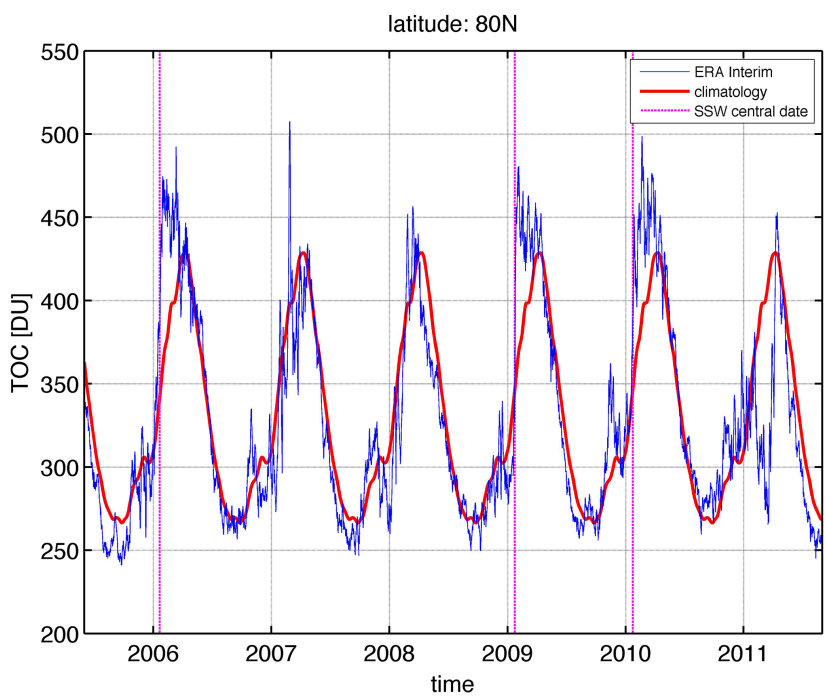

Figure 1. Time series of zonal mean TOC at $80^{\circ} \mathrm{N}$. The blue line is provided by ERA Interim reanalysis. The red line shows the mean seasonal behaviour of TOC as derived from ERA Interim reanalysis data at $80^{\circ} \mathrm{N}$ from 1979 to 2014 . The vertical, magenta lines denote the central dates of the major SSWs in 2006, 2009 and 2010. Please note the positive anomalies ( $>50 \mathrm{DU}$ ) of the blue line relative to the red line (climatology) after the onsets of the major SSW events. Xticks are always on 1 January.

the central date are added and averaged so that the mean behaviour of the atmosphere with respect to the 20 major SSWs is obtained at each latitude belt and each pressure level.

For the ensemble of the $20 \mathrm{SSWs}$, we also derive the standard deviation of the mean $\sigma$ (error of the mean) as the function of epoch time and latitude for each anomaly distribution. The mean anomalies which exceed the $2 \sigma$ level are regarded to be statistically significant with a confidence greater than $95 \%$. In the following, the viewgraphs and the discussion are only performed for the mean anomalies exceeding the $2 \sigma$ level.

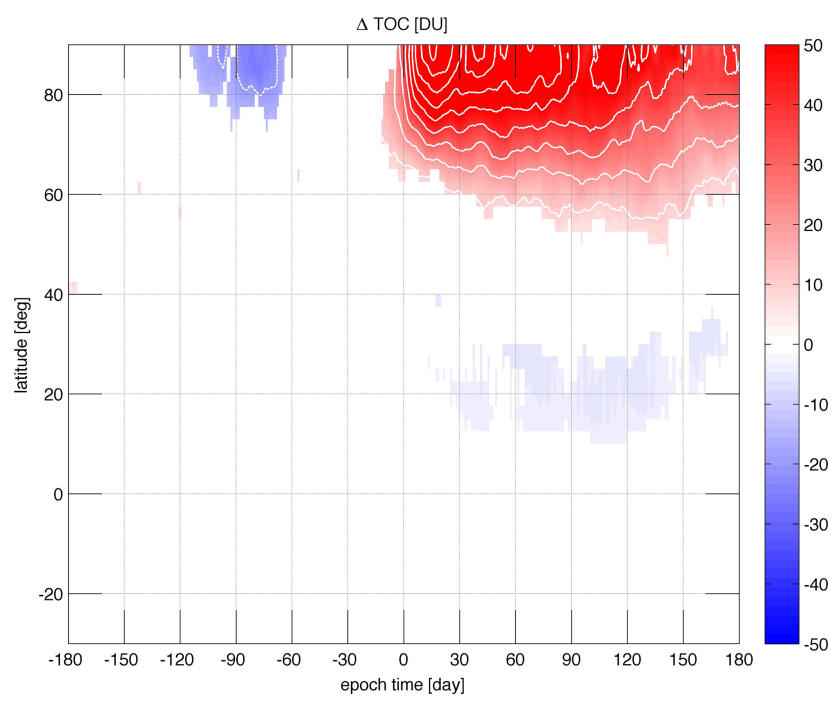

Figure 2. Composite of the anomaly $\triangle \mathrm{TOC}$ as function of epoch time ( 0 is the central date of SSW) and geographic latitude. Values are only shown if they exceed the $2 \sigma$ level where $\sigma$ is the error of the mean of the SSW ensemble. After the SSW, increased $\Delta$ TOC values of up to $90 \mathrm{DU}$ occur in the polar region. A negative anomaly of about -20 DU is present in polar ozone 90 days before the SSW. The white contour lines have a spacing of $10 \mathrm{DU}$. The composite is based on 20 major SSWs.

\section{Results}

\subsection{Composites of total ozone column}

TOC density is derived by integration of the ozone concentration over the height interval from 5 to $60 \mathrm{~km}$. Figure 1 shows an example for zonal mean TOC at $80 \mathrm{~N}$ latitude from 2005 to 2010. Three major SSWs (January 2006, 2009 and 2010) happened during this time interval. These SSWs are marked by the magenta lines and it is obvious that TOC (blue line) is enhanced by about $50 \mathrm{DU}$ with respect to the TOC climatology (red line) after the onset of the SSWs.

Quite a similar behaviour is obtained at high latitudes for the composite of the TOC anomaly of the 20 major SSWs. Figure 2 shows the composite of the anomaly $\triangle \mathrm{TOC}$ as function of epoch time $(0=$ central date of SSW $)$ and as function of geographic latitude. After the SSW, increased $\triangle T O C$ values of up to $90 \mathrm{DU}$ occur in the polar region. A negative anomaly of about $-20 \mathrm{DU}$ is present in polar ozone 90 days before the SSW. It is remarkable that the positive anomaly exists for more than half a year. This is due to the long life time of odd oxygen in the lower stratosphere and to the small meridional mixing of the polar air masses. A simulation of Liu et al. (2011) for the SSW in Arctic winter 2002-2003 gave the result that horizontal advection of ozone into the polar vortex increases significantly due to the weakening of the vortex by planetary waves. They found a pronounced in- 


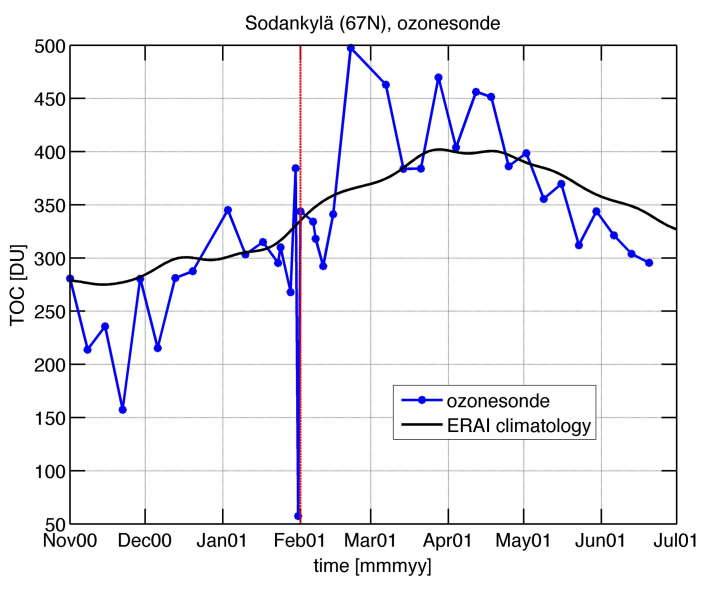

Figure 3. Total ozone derived from ozonesondes (blue line) launched at Sodankyla $\left(67^{\circ} \mathrm{N}\right)$. High TOC values ( $\left.>450 \mathrm{DU}\right)$ are reached after the SSW of February 2001 (red line), similar as in the composite of Fig. 2. The black line denotes the long-term mean at Sodankyla as derived from the ERA Interim reanalysis (19792014).

crease (26-28DU) in the polar vortex ozone due to SSW events. Figure 3 shows total ozone derived from ozonesondes launched at Sodankylä $\left(67^{\circ} \mathrm{N}\right)$ before and after the major SSW of February 2001. High TOC values of about 450 DU are measured in the months after the SSW.

\subsection{Composites of the other parameters}

Composites of the anomalies $\Delta T$ at 10 and at $1 \mathrm{hPa}$ are shown in Fig. 4. A temperature maximum of $27 \mathrm{~K}$ is reached at $10 \mathrm{hPa}$ in the polar region. Interestingly, the air temperature is enhanced in the 2 months before the SSW at $1 \mathrm{hPa}$. The cooling after the SSW at $1 \mathrm{hPa}$ is possibly associated with the cold layer below the elevated stratopause as reported by Tomikawa et al. (2012). The elevated stratopause also remained for up to 3 months after the SSW in their study. Zuelicke et al. (2015) find that $71 \%$ of the major SSWs are accompanied by an upper mesospheric cooling. Composites of the anomalies $\triangle \mathrm{PV}$ (potential vorticity) at 10 and at $1 \mathrm{hPa}$ are shown in the lower panel of Fig. 4. In the months before the SSW, $\triangle \mathrm{PV}$ is 2 times increased in the polar region at $10 \mathrm{hPa}$. After the major SSW, $\triangle \mathrm{PV}$ decreases, and this decrease spreads out from the polar to mid-latitudes in the following 3 months. The weakening or breakdown of the polar vortex after the SSW is of course reported in previous studies but it is interesting that the circulation is perturbed over 3 months. At $1 \mathrm{hPa}, \Delta \mathrm{PV}$ at mid-latitudes is decreased 30 days before the SSW and this negative anomaly propagates in the following time to high latitudes.

Composites of the anomalies $\Delta u$ at 10 and at $1 \mathrm{hPa}$ are shown in Fig. 5. A negative anomaly of eastward wind of $-59 \mathrm{~m} \mathrm{~s}^{-1}$ is reached at $1 \mathrm{hPa}$, connected with the breakdown and the reversal of the vortex after the SSW. The nega-
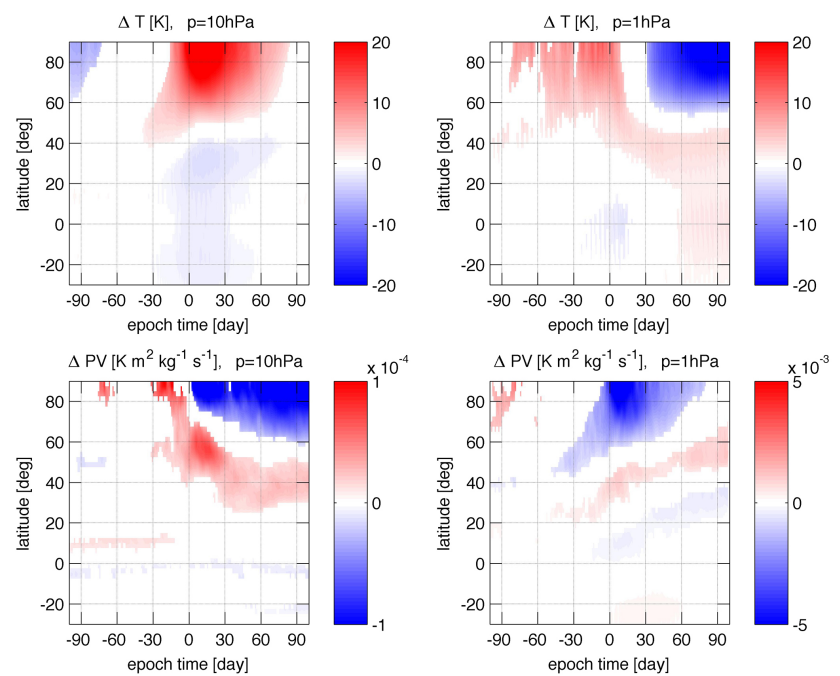

Figure 4. Composites of the anomalies $\Delta T$ at $10 \mathrm{hPa}$ (upper left) and at $1 \mathrm{hPa}$ (upper right). Values are only shown if they exceed the $2 \sigma$ level. Temperature maximum of $27 \mathrm{~K}$ is reached at $10 \mathrm{hPa}$. Composites of the anomalies $\triangle \mathrm{PV}$ at 10 and at $1 \mathrm{hPa}$ are shown in the lower panel. The composites are based on 20 major SSWs.
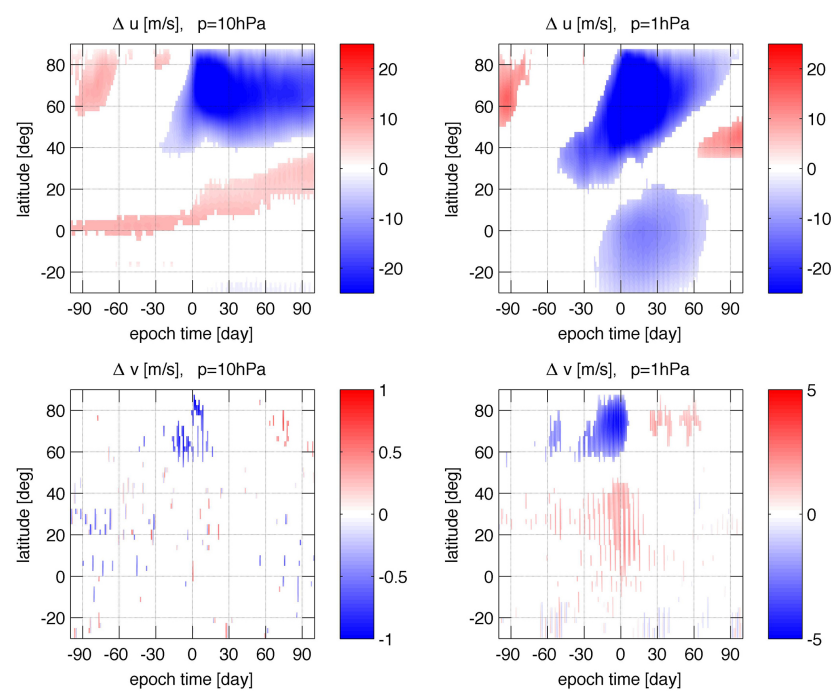

Figure 5. Composites of the anomalies $\Delta u$ at $10 \mathrm{hPa}$ (upper left) and at $1 \mathrm{hPa}$ (upper right). Values are only shown if they exceed the $2 \sigma$ level. Eastward wind anomaly of $-59 \mathrm{~m} \mathrm{~s}^{-1}$ is reached at $1 \mathrm{hPa}$. Composites of the anomalies $\Delta v$ at 10 and at $1 \mathrm{hPa}$ are shown in the lower panel.

tive values of $\Delta u 30$ days before the SSW at mid-latitudes at $1 \mathrm{hPa}$ are remarkable. It seems that the anomaly started at the mid-latitude stratopause and propagated poleward until the SSW onset. At $10 \mathrm{hPa}, \Delta u$ at mid- and high latitudes remains negative (westward anomaly) up to 3 months after the SSW. In some of the previous composite studies (e.g. Miller et al. (2013), the zonal wind switches back to eastward direction 5 to 10 days after the SSW. This is certainly true if the com- 

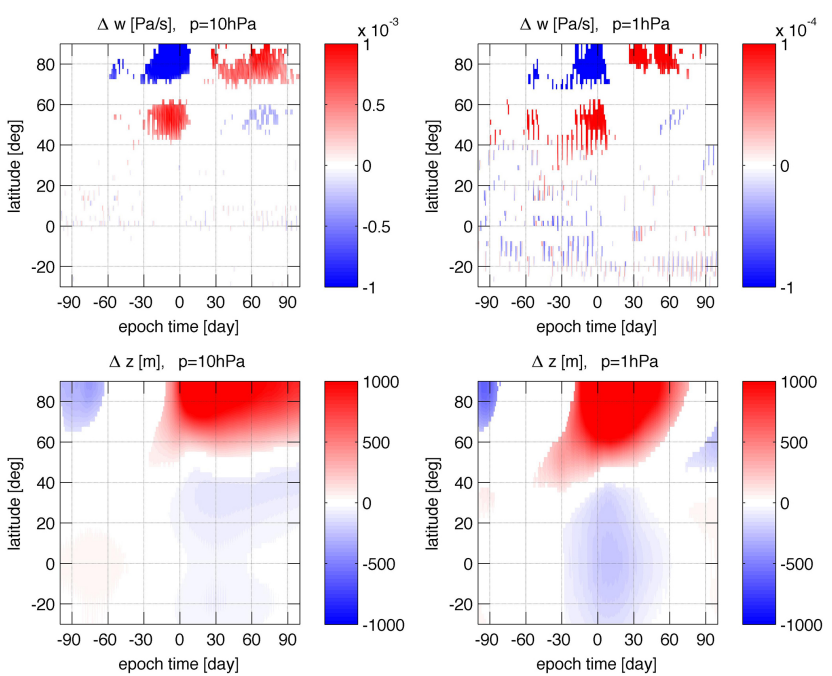

Figure 6. Composites of the anomalies $\Delta w$ (positive $=$ downward) at $10 \mathrm{hPa}$ (upper left) and at $1 \mathrm{hPa}$ (upper right). Values are only shown if they exceed the $2 \sigma$ level. Composites of the anomalies $\Delta z$ at $10 \mathrm{hPa}$ and at $1 \mathrm{hPa}$ are shown in the lower panel. A maximal, upward shift of $2900 \mathrm{~m}$ is reached for the $1 \mathrm{hPa}$ geopotential height (lower right).

posite is taken for the absolute zonal wind values (and not for the anomalies with respect to the climatological mean). The composite analysis of anomalies seems to foster the recognition of precursors and the effects of SSWs. It should be noted that several previous studies also discussed composites of anomalies. However, the derivation of the anomalies was performed by means of leading principal component (PC) time series analysis (e.g. Limpasuvan et al. (2004)) which actually cannot fetch the climatological mean as the reference for the SSW anomaly.

Composites of the anomalies $\Delta v$ at 10 and at $1 \mathrm{hPa}$ are shown in the lower panel of Fig. 5. It is evident that a southward wind anomaly (blue) prevailed in the polar region before the SSW. This is in agreement with the enhanced meridional heat flux anomaly before the SSW, as reported by Charlton and Polvani (2007).

Composites of the anomalies $\Delta w$ (positive $=$ downward) at $10 \mathrm{hPa}$ and at $1 \mathrm{hPa}$ are shown in Fig. 6. In the polar region there is upwelling (blue) before the SSW and downwelling (red) after the SSW. However, it is surprising that the downwelling in the polar region starts 30 days after the SSW. At mid-latitudes, the behaviour is vice versa, with downwelling (red) before and during the SSW. Composites of the geopotential height anomalies $\Delta z$ at 10 and at $1 \mathrm{hPa}$ are shown in the lower panel of Fig. 6. At $1 \mathrm{hPa}$, at mid-latitudes, the geopotential height (or pressure) increases 30 days before the SSW. Similar to the zonal wind, the geopotential height perturbation travels poleward. In addition, at $10 \mathrm{hPa}$ and about 10 days before the SSW, there is an increase in geopotential height. A maximal, upward shift of $2900 \mathrm{~m}$ is reached for the
$1 \mathrm{hPa}$ geopotential height. The pressure increase remains for 60 to 90 days after the SSW. The increase of the geopotential height anomaly before, during, and after the SSW at $50 \mathrm{hPa}$ is shown in Limpasuvan et al. (2004).

In summary, there are several precursors of the SSW, visible in the stratopause region $(u, z)$ and in the midstratosphere $(\mathrm{PV}, v)$. The stratosphere seems to be most promising for prediction of major SSWs at mid-latitudes. Forecast of an individual SSW remains difficult since the variability of the winter stratosphere might be larger than the precursor signals.

\section{Conclusions}

The study showed that it is valuable to take climatology as the reference for the SSW anomaly and to analyse the composites on a longer interval of epoch time (e.g. from 3 months before, to 3 months after the SSW central date). We quantitatively described the average behaviour of a major SSW in the anomalies of total ozone column density (TOC), temperature $(T)$, potential vorticity $(\mathrm{PV})$, eastward wind $(u)$, northward wind $(v)$, vertical wind $(w)$, and geopotential height $(z)$. Interestingly, some parameters $(T, u, z)$ already show an anomaly 1-2 months before the major SSW onset. For example, the geopotential height of the $1 \mathrm{hPa}$ level at mid-latitudes increases more than 1 month before the major SSW. The meridional propagation of the initial SSW anomaly from mid-latitudes to high latitudes is also seen in $\Delta u$ and might be based on the connection between Rossby waves and SSWs. The significant features in the anomaly viewgraphs may help to further understand the life cycle of SSWs. There might be a small chance for long-term prediction of a major SSW if all characteristics are taken into account, for example, the probability of a SSW could be calculated 1 or 2 months ahead. The anomaly of total ozone (Fig. 2) showed the long-lasting effect ( $>6$ months) of a major SSW on the atmospheric composition in the polar stratosphere nicely.

Acknowledgements. We thank Professors J. J. Oh and N. Kämpfer for the past project "Precursors and Effects of SSWs at Bern and Seoul" of the Strategic Korean-Swiss Cooperative Program. ERA Interim reanalysis data were provided by the European Center for Medium-range Weather Forecast (ECMWF). We thank E. Kyrö and the Sodankylä observatory for the ozone sonde data which were distributed by the Network for the Detection of Atmospheric Composition Change (NDACC). We also thank the International Space Science Institute (Bern, Switzerland) for hosting three science teams on sudden stratospheric warmings (N. Pedatella, L. Goncharenko and P. Hoffmann) giving ideas and motivation for the article, e.g. Hanli Liu suggested to take the climatology as the reference for the SSW anomaly. Finally we thank the two reviewers for suggesting the significance analysis and a broader review of related works.

The topical editor C. Jacobi thanks two anonymous referees for help in evaluating this paper. 


\section{References}

Baldwin, M. P. and Dunkerton, T. J.: Stratospheric harbingers of anomalous weather regimes, Science, 294, 581-584, 2001.

Charlton, A. J. and Polvani, L. M.: A new look at stratospheric sudden warmings, Part I: Climatology and modeling benchmarks, J. Climate, 20, 449-469, 2007.

Dee, D. P., Uppala, S. M., Simmons, A. J., Berrisford, P., Poli, P., Kobayashi, S., Andrae, U., Balmaseda, M. A., Balsamo, G., Bauer, P., Bechtold, P., Beljaars, A. C. M., van de Berg, L., Bidlot, J., Bormann, N., Delsol, C., Dragani, R., Fuentes, M., Geer, A. J., Haimberger, L., Healy, S. B., Hersbach, H., Hólm, E. V., Isaksen, L., Kållberg, P., Köhler, M., Matricardi, M., McNally, A. P., Monge-Sanz, B. M., Morcrette, J.-J., Park, B.-K., Peubey, C., de Rosnay, P., Tavolato, C., Thépaut, J.-N., and Vitart, F.: The ERA-Interim reanalysis: configuration and performance of the data assimilation system, Q. J. Roy. Meteor. Soc., 137, 553-597, doi:10.1002/qj.828, 2011.

Flury, T., Hocke, K., Haefele, A., Kämpfer, N., and Lehmann, R.: Ozone depletion, water vapor increase, and PSC generation at midlatitudes by the 2008 major stratospheric warming, J. Geophys. Res.-Atmos., 114, D18302, doi:10.1029/2009JD011940, 2009.

Limpasuvan, V., Thompson, D. W. J., and Hartmann, D. L.: The life cycle of the Northern Hemisphere sudden stratospheric warmings, J. Climate, 17, 2584-2596, 2004.

Liu, Y., Liu, C. X., Tie, X. X., and Gao, S. T.: Middle stratospheric polar vortex ozone budget during the warming Arctic winter, 2002-2003, Adv. Atmos. Sci., 28, 985-996, 2011.

Marshall, A. G. and Scaife, A. A.: Improved predictability of stratospheric sudden warming events in an atmospheric general circulation model with enhanced stratospheric resolution, J. Geophys. Res.-Atmos., 115, D16114, doi:10.1029/2009JD012643, 2010.

Martius, O., Polvani, L. M., and Davies, H. C.: Blocking precursors to stratospheric sudden warming events, Geophys. Res. Lett., 36, L14806, doi:10.1029/2009GL038776, 2009.
Matsuno, T.: Dynamical Model of Stratospheric Sudden Warming, J. Atmos. Sci., 28, 1479-1494, 1971.

Matthewman, N. J., Esler, J. G., Charlton-Perez, A. J., and Polvani, L. M.: A New Look at Stratospheric Sudden Warmings, Part III: Polar Vortex Evolution and Vertical Structure, J. Climate, 22, 1566-1585, 2009.

McInturff, R.: Stratospheric warmings: Synoptic, dynamic and general circulation aspects, NASA References Publ. NASA-RP1017, Natl. Meteorol. Cent., Washington D.C., USA, 166 pp., 1978.

Miller, A., Schmidt, H., and Bunzel, F.: Vertical coupling of the middle atmosphere during stratospheric warming events, J. Atmos. Sol.-Terr. Phy., 97, 11-21, doi:10.1016/j.jastp.2013.02.008, 2013.

Scherhag, R.: Die explosionsartige Stratosphärenerwärmung des Spätwinters 1951/52, Ber. Deutsch. Wetterdienstes, 38, 51-63, 1952.

Schoeberl, M. R.: Stratospheric Warmings - Observations and Theory, Rev. Geophys., 16, 521-538, 1978.

Smith, A. K.: Preconditioning for Stratospheric Sudden Warmings - Sensitivity Studies with a Numerical-Model, J. Atmos. Sci., 49, 1003-1019, 1992.

Taguchi, M.: Is there a statistical connection between stratospheric sudden warming and tropospheric blocking events?, J. Atmos. Sci., 65, 1442-1454, 2008.

Tomikawa, Y., Sato, K., Watanabe, S., Kawatani, Y., Miyazaki, K., and Takahashi, M.: Growth of planetary waves and the formation of an elevated stratopause after a major stratospheric sudden warming in a T213L256 GCM, J. Geophys. Res.-Atmos., 117, D16101, doi:10.1029/2011JD017243, 2012.

Zuelicke, C., Becker, E., Matthias, V., Peters, D. H. W., Schmidt, H., Liu, H.-L., de la Torre Ramos, L., and Mitchell, D. M.: Mesospheric coolings and stratospheric warmings in observations and simulations, J. Clim., submitted, 2015. 